\title{
Dermatology research in primary care: why, what, and how?
}

In their seminal report into primary care research and development, Mant observed that there was:

\section{'... a serious mismatch between the financial and clinical importance to the NHS of decisions made in primary care and the available evidence and research capacity in this sector.'}

Primary care research is much stronger than it was when this report was published in 1997, but it is still the case that while the majority of care takes place in primary care, clinicians often have to make decisions in an evidence void. Where research exists, it has commonly been conducted in patients who are not typical of the primary care population. For example, skin problems, ${ }^{2}$ disorders of the digestive system, ${ }^{3}$ and allergy-related ${ }^{4}$ problems are commonly seen in primary care, but a recent review of UK primary care research activity highlighted a paucity of studies conducted in primary care. ${ }^{5}$

The case for more primary care based dermatology research is particularly pressing. Skin conditions are the most common reason for people to consult their GP with a new problem. ${ }^{2}$ According to a recent report on health care needs for skin conditions, almost one-quarter (24\%) of the population in England and Wales (12.9 million people) visited their GP with a skin problem in 2006. ${ }^{2}$ Eczema, acne, and psoriasis are the chronic skin disorders most frequently seen, ${ }^{2}$ with the majority of patients being managed in primary care: only $4 \%$ of children with eczema ${ }^{6}$ and $0.3 \%$ of patients with acne ${ }^{7}$ see a dermatologist.

Quality of life is reported to be significantly poorer for these patients such that the impact of their conditions may be greater than for life-threatening diseases such as cancer. ${ }^{2}$ While these findings have mainly been conducted in dermatology out-patient clinics, there is some evidence that patients seen in primary care also have significant physical, social, and psychological impairments. ${ }^{8,9}$

Dermatology research appears to be neglected at both national and primary care levels. In 2006 The UK Clinical Research Collaboration published an analysis of the directly-funded UK research portfolios of the 11 largest government and charity funders of health-related research. In terms of the combined proportion of funding of 20 health categories, 'skin' ranked eighteenth, followed only by 'injuries' and 'other'. Perhaps it is hardly surprising then that in this broader context, there is very little primary care dermatology research. ${ }^{5}$ The evidence from ISI Web of Knowledge is that other countries have a similar deficit in primary care dermatology research at present. Kruschinski et $a /^{10}$ retrospectively examined all of the abstracts presented at each of the 14 European General Practice Research Network conferences between 2001 and 2007: dermatology did not appear as a topic in any of the 614 abstracts. At the 2010 UK annual scientific meeting of The Society for Academic Primary Care, of the 257 abstracts featured only one was dermatological. ${ }^{11}$

If this disparity between clinical and research activity is to be redressed, then where to begin? Initially, just highlighting the issue to funders, researchers, and clinicians may help to stimulate funding, delivery, and engagement in primary care dermatology research. For example, subsequent to the second 'Mackenzie report' in 2002, ${ }^{12}$ which described a dearth musculoskeletal research from primary care, there was a significant increase in the number of publications in this area.

The remit of primary care dermatology is very broad, making the identification of priorities especially challenging. NHS evidence maintains the Database of Uncertainties about the Effects of Treatments that includes skin topics, to which patients and clinicians can contribute, but currently no attempt is made to prioritise the research questions listed. ${ }^{13}$ Should priority be given to the conditions most commonly seen in primary care, or to those where there are the greatest concerns about harms or costeffectiveness, or to those where research would be most timely; for example, research on the acceptability and efficacy of emollients in eczema where there are currently moves to limit choice on the grounds of cost alone?

One way to set priorities in research is to engage in explicit processes, such as those promoted by the James Lind Alliance. ${ }^{14}$ But who should contribute to this exercise? Similar exercises conducted in other neglected areas have taught us that the process is labour intensive and there can be a poor agreement between the priorities of patients, clinicians, and researchers. ${ }^{15}$ Even within a specific condition, such as eczema, a large number of treatment uncertainties can be generated. Interestingly, the James Lind Alliance invites patients, carers, and health professionals to take part in their prioritisation exercises, but specifically excludes researchers who may be driven by competing interests. ${ }^{14}$

Primary care research has come a long way since its early days, supported now through the national schools of primary care research in England, Scotland, and Wales and the Primary Care Research Networks. ${ }^{16}$ If priorities for research can be agreed and funding made available, then these organisations are ideally placed to facilitate the development and delivery of a portfolio of primary care dermatology research in the UK.

Interested clinicians and researchers can engage with the UK Dermatology Clinical Trials Network, which has a trial prioritisation and generation panel, as well as structures and support for developing trial ideas. ${ }^{17}$

However, engaging GPs who do not have a specific interest in research remains a challenge and this may be especially so 
for dermatological conditions where some treatments may be ingrained and awareness of treatment uncertainties poor. For example, the use of antibiotics for possible 'infective flares' of eczema in general practice is commonplace,$^{18}$ but the role of Staphylococcus aureus is far from clear. ${ }^{19}$ Randomised controlled trials in primary care may be the way to answer definitively this kind of research question; but for GPs to be willing to refer incident cases of a condition, they will need to be convinced of the clinical equipoise and want any additional workload to be minimised. The key to meaningful and successful primary care dermatology research will be to engage with the important, answerable questions and make it straightforward for clinicians and patients to take part.

\section{Matthew Ridd,}

NIHR Clinical Lecturer, School of Social and Community Medicine, University of Bristol, Bristol.

\section{Kim Thomas,}

Associate Professor and Deputy Director of the Centre of Evidence Based Dermatology, University of Nottingham, Nottingham.

\section{Paul Wallace,}

Professor of Primary Health Care and Director of NIHR Primary Care Research Network, Department of Primary Care and Population Health, University College London, London.

\section{Frank O'Sullivan,}

Professor of Primary Health Care and Director of Scottish School of Primary Care, University of Dundee, Dundee.

\section{Provenance}

Commissioned, not externally peer reviewed.

\section{REFERENCES}

1. Mant D. ReD in primary care: National working Group report. Leeds: NHS Executive, 1997.

2. Schofield J, Grindlay D, Williams H. Skin conditions in the UK: a health care needs assessment. Nottingham: Centre of Evidence Based Dermatology, University of Nottingham, 2009.

3. Williams JG, Roberts SE, Ali MF, et al. Gastroenterology services in the UK. The burden of disease, and the organisation and delivery of services for gastrointestinal and liver disorders: a review of the evidence. Gut 2006; 56(Suppl 1): 1-113.

4. Royal College of Physicians. Allergy: the unmet need. A blueprint for better patient care. Report of a working party. London: RCP, 2003.

5. Sullivan F, Wallace P. UK primary care research portfolio review. Dundee: Scottish School of Primary Care Research, 2010.

http://www.sspc.ac.uk/documents/final_port_review (accessed 13 Jan 2011)

6. Emerson RM, Williams HC, Allen BR. Severity distribution of atopic dermatitis in the community and its relationship to secondary referral. Br J Dermatol 139(1): 73-76.

7. Purdy S, de Berker D. Acne. BMJ 2006; 333(7575): 949-953.

8. Harlow D, Poyner T, Finlay AY, Dykes PJ. Impaired quality of life of adults with skin disease in primary care. Br J Dermatol 2000; 143(5): 979-982.

9. Verhoeven EW, Kraaimaat F, van de Kerkhof PC, et al. Psychosocial well-being of patients with skin diseases in general practice. J Eur Acad Dermatol Venereol 2007; 21(5): 662-668.

10. Kruschinski C, Lange M, Lionis C, et al. Themes and methods of research presented at European General Practice Research Network conferences. Fam Pract 2010; 27(4): 459-467.

11. The Society for Academic Primary Care East. 39th Annual Scientific Meeting: programme and abstracts. Oxford: Society for Academic Primary Care, 2010.

12. Society for Academic Primary Care (SAPC). New century, new challenges: a report from the Heads of Departments of General Practice and Primary Care in the Medical Schools of the United Kingdom. London: Royal College of General Practitioners, 2002.

13. NHS Evidence. UK Database of Uncertainties about the Effects of Treatments (DUETs). http://www.library.nhs.uk/duets (accessed 23 Dec 2010).
14. The James Lind Alliance. http://www.lindalliance.org (accessed 23 Dec 2010).

15. Buckley BS, Grant AM, Tincello DG, et al. Prioritizing research: patients, carers, and clinicians working together to identify and prioritize important clinical uncertainties in urinary incontinence. Neurol Urodyn 2010; 29(5): 708-714.

16. Sullivan F, Butler C, Cupples M, Kinmouth AL. Primary care research networks in the United Kingdom. BMJ 2007; 334(7603): 1093-1094.

17. UK Dermatology Controlled Trials Network. http://www.ukdctn.org (accessed 23 Dec 2010).

18. Santer M, Lewis-Jones S, Fahey T. Appropriateness of prescribing for childhood eczema: evidence from a community-based study. Clin Exp Dermatol 2006; 31(5): 671-673.

19. Birnie AJ, Bath-Hextall FJ, Ravenscroft JC, Williams HC. Interventions to reduce Staphylococcus aureus in the management of atopic eczema. Cochrane Database Syst Rev 2008; (3): CD003871.

DOI:10.3399/bjgp11X556173

\section{ADDRESS FOR CORRESPONDENCE}

\section{Matthew Ridd}

School of Social and Community Medicine, University of Bristol, 39 Watley Road,

Bristol BS8 2PS.

E-mail: m.ridd@bristol.ac.uk 